\title{
Distribution and diversity of olefins and olefin-biosynthesis genes in Gram-positive bacteria
}

\author{
Maximilian Surger, Angel Angelov and Wolfgang Liebl ${ }^{*}$ (i)
}

\begin{abstract}
Background: The natural production of olefins (unsaturated aliphatic hydrocarbons) by certain bacterial genera represents an alternative and sustainable source of biofuels and lubricant components. The biochemical steps of olefin biosynthesis via the ole pathway encoded by oleABCD have been unraveled recently, and the occurrence of olefins has been reported for several Gram-negative and Gram-positive bacteria. However, the distribution and diversity of olefins among the Gram-positive bacteria has not been studied in detail.

Results: We report the distribution of olefin synthesis gene clusters in the bacterial domain and focus on the olefin composition and the determinants of olefin production within the phylum of Actinobacteria. The olefin profiles of numerous genera of the Micrococcales order were analyzed by GC/MS. We describe for the first time olefin synthesis in representatives of the genera Pseudarthrobacter, Paenarthrobacter, Glutamicibacter, Clavibacter, Rothia, Dermacoccus, Kytococcus, Curtobacterium, and Microbacterium. By exchange of the native ole genes of Micrococcus luteus with the corresponding genes of actinobacteria producing different olefins, we demonstrate that the olefin composition can be manipulated with respect to chain length and isomer composition.

Conclusions: This study provides a catalogue of the diversity of olefin structures found in the Actinobacteria. Our ole gene swapping data indicate that the olefin structures are fundamentally determined by the substrate specificity of OleA, and at the same time by the availability of a sufficient supply of suitable fatty acyl-CoA substrates from cellular fatty acid metabolism. This makes OleA of Gram-positive bacteria a promising target for structural analysis and protein engineering aiming to generate olefin chain lengths and isomer profiles which are designed to match the requirements of various industrial applications.
\end{abstract}

Keywords: Micrococcales, Micrococcus luteus, OleABCD, Phylogenetics, Olefin diversity, OleA

\section{Background}

Owing to the limited resources for fossil fuels and the ethical conflict over plant oil-derived fuels competing with food agriculture, synthesis of hydrocarbons in metabolically engineered microorganisms has become a sustainable alternative (Pfleger et al. [11]). The current routes for synthesis of diverse microbial hydrocarbons

\footnotetext{
*Correspondence: wliebl@wzw.tum.de

Chair of Microbiology, Technical University of Munich, Emil-Ramann-Str. 4,

85354 Freising-Weihenstephan, Germany
}

are largely based on fatty acid metabolism, and the enzymatic steps of the ole pathway (olefin synthesis pathway encoded by the operon ole $A B C D$, consisting of the genes $o l e A, o l e B C$, and oleD) have been completely elucidated within the last few years. In the first reaction of this pathway (Fig. 1), catalyzed by OleA (protein encoded by $o l e A$ ), two activated fatty acids undergo a non-decarboxylative head-to-head Claisen condensation that results in a $\beta$-keto acid. This intermediate acid is transferred without temporary release to the OleBCD complex, where it is reduced to a $\beta$-hydroxy acid by the NADH-dependent 


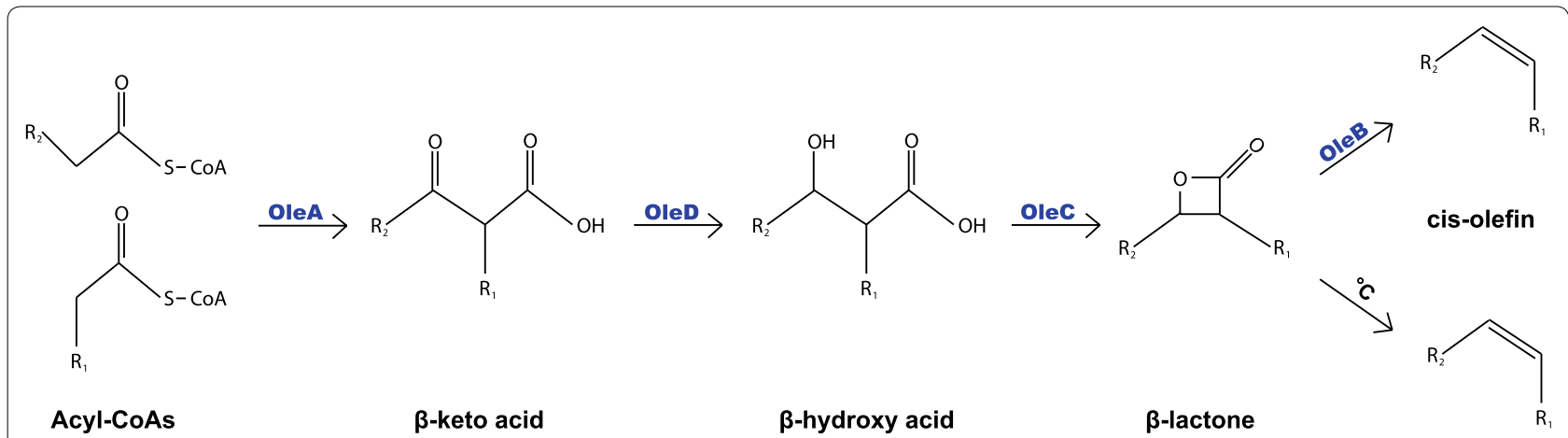

Fig. 1 Olefin biosynthesis via the ole pathway according to Christenson et al. [6]. The thiolase OleA converts two acyl-CoAs in a non-decarboxylating "head-to-head" Claisen condensation to a $\beta$-keto acid. In a NADPH-dependent reaction, the dehydrogenase OleD reduces the $\beta$-keto acid to the corresponding $\beta$-hydroxy acid. The $\beta$-lactone synthetase OleC converts the $\beta$-hydroxy acid into a heat-unstable $\beta$-lactone. Finally, OleB decarboxylates the $\beta$-lactone to the cis olefin

dehydrogenase OleD. The lactone synthase OleC forms a heat-labile internal ester between the $\beta$-hydroxy and the carboxyl group and one molecule of water is released. Finally, the lactone decarboxylase OleB liberates one molecule of $\mathrm{CO}_{2}$ and converts the internal lactone into an alkene with a cis-configured internal double bond (internal olefins) at the connection point of the two original fatty acid precursors (Beller et al. [3]) (Sukovich et al. [14]) (Frias et al. [7]) (Christenson et al. [4]) (Christenson, Richman et al. [6]) (Christenson, Jensen et al. [5]).

The nature of such internal olefin hydrocarbons was first characterized in the Gram-positive Sarcina lutea (now Kocuria rhizophila) (Albro and Dittmer [1]) (Tornabene et al. [17]), and the ole $A B C D$ genes were first described in the Gram-positive Micrococcus luteus NCTC2665 (Beller et al. [3]). Nevertheless, the catalytic mechanism of OleA as well as the order and nature of the reaction steps of the OleABCD enzymes, as summarized above, were finally elucidated mainly in the Gram-negative species Shewanella oneidensis (Sukovich et al. [14]) and Xanthomonas campestris (Frias et al. [7]) (Christenson et al. [4]) (Christenson et al. [6]) (Christenson et al. [5]). In addition, the first report on the phylogenetic distribution and diversity of olefin production in bacteria by Sukovich et al. [13] described bacterial olefin production as a predominately Gram-negative capability using species from four Gram-negative phyla (Proteobacteria, Planctomycetes, Chloroflexi, Verrucomicrobia) and one Gram-positive phylum (Actinobacteria) (Sukovich et al. [13]).

Regarding the potential application of such hydrocarbons as substitute fuels, it must be noted that a perfect substitute should be chemically identical to the existing fossil fuels, which are straight-chain and isobranched C8-18 alkenes and alkanes. The spectrum of olefins from Gram-negative bacteria consists due to a predominantly straight-chain unsaturated fatty acid synthesis of C28-C31 monoalkenes, dienes, trienes and especially nonaenes, while Gram-positive bacteria due to their predominant branched chain fatty acid synthesis produce a spectrum of iso-branched, anteiso-branched, and straight-chain C20-30 monoalkenes (Sukovich et al., [13]). The fatty acid synthesis of Gram-positive bacteria is based primarily on the elongation of branched chain acyl-CoA primers, which is in contrast to Gramnegative bacteria where acetyl-CoA is exclusively used as a primer molecule. Those branched chain primers are provided by the branched chain amino acid catabolism, whose key enzymes have recently been described for the high-GC (high guanine plus cytosine content of the genome) Gram-positive Micrococcus luteus (Surger et al. [16]). Thus, olefins from Gram-positive bacteria by nature and without additional metabolic or protein engineering more closely resemble current fossil fuels than those from Gram-negative bacteria. Existing cracking technology could be applied to reduce the chain length of the Gram-positive olefins to make them better suited as drop-in fuels, i.e., compounds that can be added to existing fuels without further modification. On the other hand, also the native medium-chain olefins may be exploited as valuable constituents of lubricant formulations if they can be produced efficiently in high yields at economically viable costs.

This report provides an extensive survey about the great diversity of olefins produced by Gram-positive bacteria and creates a catalogue of Gram-positive olefin producers, making their OleABCD biosynthetic enzymes accessible for future biotechnological applications. Within the phylum Actinobacteria, we provide a detailed insight into the diversity of the fatty acid and olefin profiles of several strains per Gram-positive genus. Furthermore, we used ole $A B C D$ cluster and oleA exchange 
(See figure on next page.)

Fig. 2 Occurrence of ole gene clusters in the bacterial tree of life. a Species containing ole gene clusters are marked with a black circle. The phylogenetic tree is adapted from [dataset] Segata et al. [12] and contains 3530 bacterial species. For selected families, the number of ole gene-containing species out of all the species in the tree is shown (black text). Similarity network analysis of OleA protein sequences between members of the same and all other ole gene cluster-possessing phyla. b A horizontal gene transfer event is marked using a black arrow

mutants to investigate to which extent the diversity of actinobacterial olefin profiles is determined by the substrate specificity of the OleABCD enzymes.

\section{Results}

Distribution of oleABCD genes within the bacterial domain Using a combination of PROSITE pattern search and analysis of the gene neighborhood of potential OleA hits, we could detect ole $A B C D$ gene clusters in 1082 bacterial genomes, including incomplete genomes. No putative ole clusters could be detected in Archaea or Eukarya, as well as in some bacterial phyla (e.g., Firmicutes and Bacteroidetes). Mapping the ole cluster-containing genomes on the phylogenetic tree of Segata et al. [12] (underlying data available on https://github.com/angelovangel/oleAdistribution-paper-dataset) revealed that the ole genecontaining species are found in very diverse phylogenetic groups, forming in total seven clusters (three in the Proteobacteria, two in the Actinobacteria and one each in the Chloroflexi, Planctomycetes and Verrucomicrobia) (Fig. 2a). Notably, the distribution pattern of ole gene clusters was almost always ubiquitous at the genus rank level (i.e., all the members of a phylogenetic genus either did or did not possess ole gene clusters). Using similarity network analysis of OleA protein sequences, it was found that the OleA protein sequences in each phylum were more similar to each other than to proteins from the other phyla (Fig. 2b). This observation suggests an ancient origin of the protein, in general. Nevertheless, the clustering of OleA from the Proteobacteria species Pseudohaleia rubra with the OleAs from the Actinobacteria was observed too, which indicates that rare lateral gene transfer events have occurred.

\section{Diversity of olefin and fatty acid profiles in the Micrococcales order}

Within the phylum Actinobacteria, the ole $A B C D$ gene cluster-possessing genera were mostly found in the order Micrococcales. In order to expand the available structural and phylogenetic information about the olefins within this bacterial order, we acquired and analyzed 65 strains, belonging to the genera Micrococcus, Kocuria, Arthrobacter, Brevibacterium/Curtobacterium (homotypic synonyms), Glutamicibacter, Clavibacter, Dermacoccus, Kytococcus, Microbacterium, Paenarthrobacter, Pseudarthrobacter, and Rothia, for their potential olefin production capacity. The strains were grown in a complex medium at $30^{\circ} \mathrm{C}$ to stationary phase and olefins and total fatty acids for each isolate were extracted and analyzed by GC/MS (gas chromatography/mass spectrometry). An overview of the olefin profiles and amounts produced by the investigated genera can be seen in Fig. 3, which shows a representative average of all isolates that could be assigned to the respective genera. It is noteworthy that the total amounts of olefins produced (normalized to optical densities of the cultures) revealed considerable variation between different strains belonging to the same genus, but the chain length and isomer profiles were usually similar within each genus. Additional files 1, 2, 3, 4, 5: Figures S1-S5 provide detailed reports on the olefin and fatty acid profiles of all single strains. Assuming a constant ratio of cell numbers per optical density and taking the comparable fatty acid levels for all Micrococcales strains into account, the total amounts produced by Kocuria strains were remarkable. In contrast, Micrococcus, Microbacterium, Kytococcus, Paenarthrobacter, and Rothia strains produced, on average, five times less than Kocuria strains, and Arthrobacter, Pseudarthrobacter, Brevibacterium/Curtobacterium, Clavibacter, and Dermacoccus strains produced only traces of olefins. The average olefin chain lengths in the order Micrococcales ranged from 27 to 29 carbon atoms, with the latter being the dominant length. The average olefin isomer profile, as expected for Gram-positive bacteria with predominant branched chain fatty acid synthesis, consisted exclusively of iso- and anteiso (ai)-branched carbon chains. The isomers were dominated by anteisoanteiso (aiai)-branched olefins. The genus Kocuria was again an exception. The chain lengths produced in this genus ranged from 21 to 27 carbon atoms, which means that the olefins were considerably shorter than the average Micrococcales olefins. Strain Ky. sedentarius TW93 also revealed an unusual Micrococcales olefin profile. It produced chain lengths of 21 to 25 carbons, similar to those from Kocuria strains, but also of 27 to 29 carbon atoms, similar to the average length produced by Micrococcales strains. In addition, Kocuria and Kytococcus strains showed notably greater shares of isoiso-branched (iso-branched at both ends) olefins and were able to produce also straight-chain olefins. A common spectrum of 14 to 17 carbon atoms long, especially $a i$-branched and saturated fatty acids, was observed in all Micrococcales strains. The fatty acid 


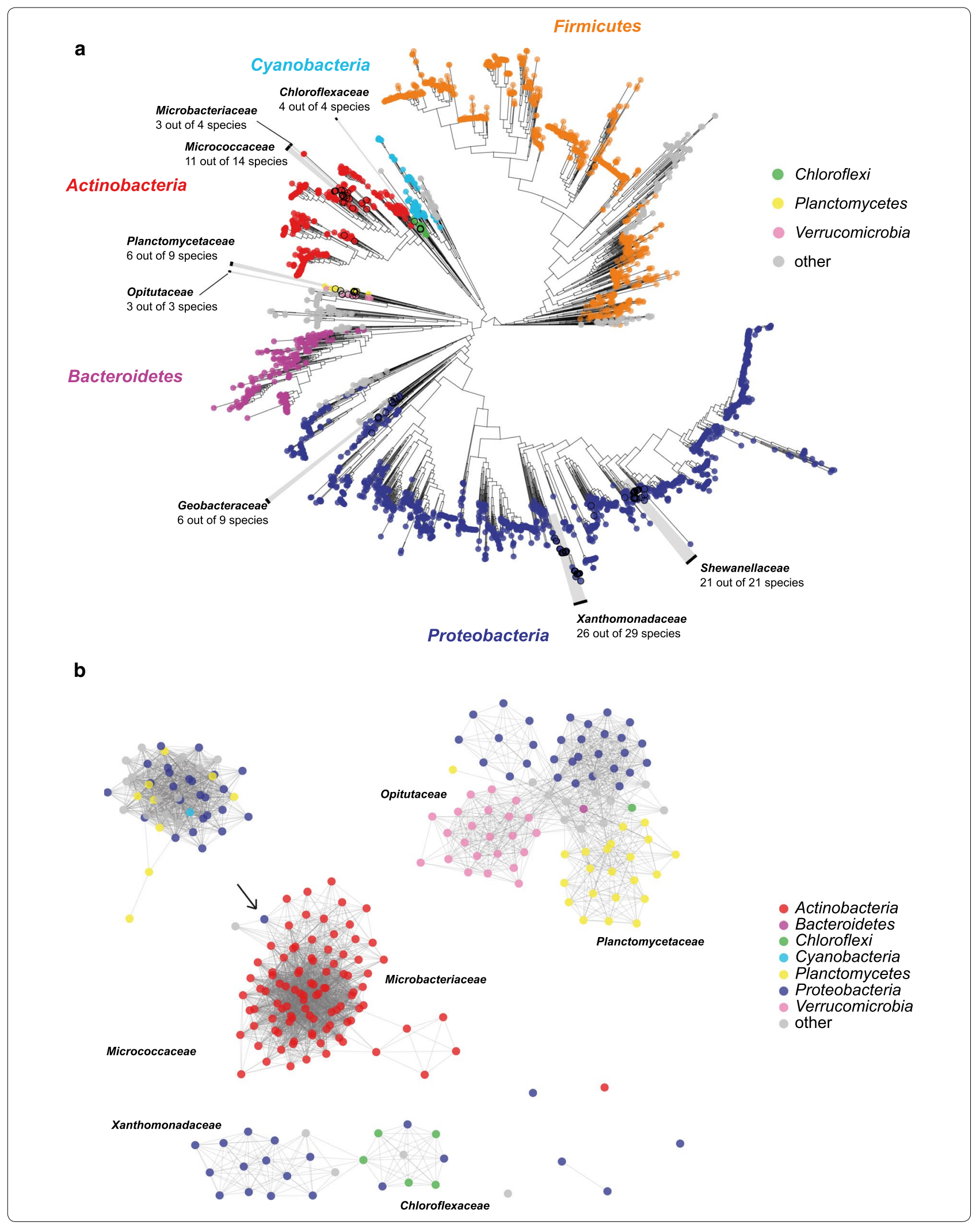




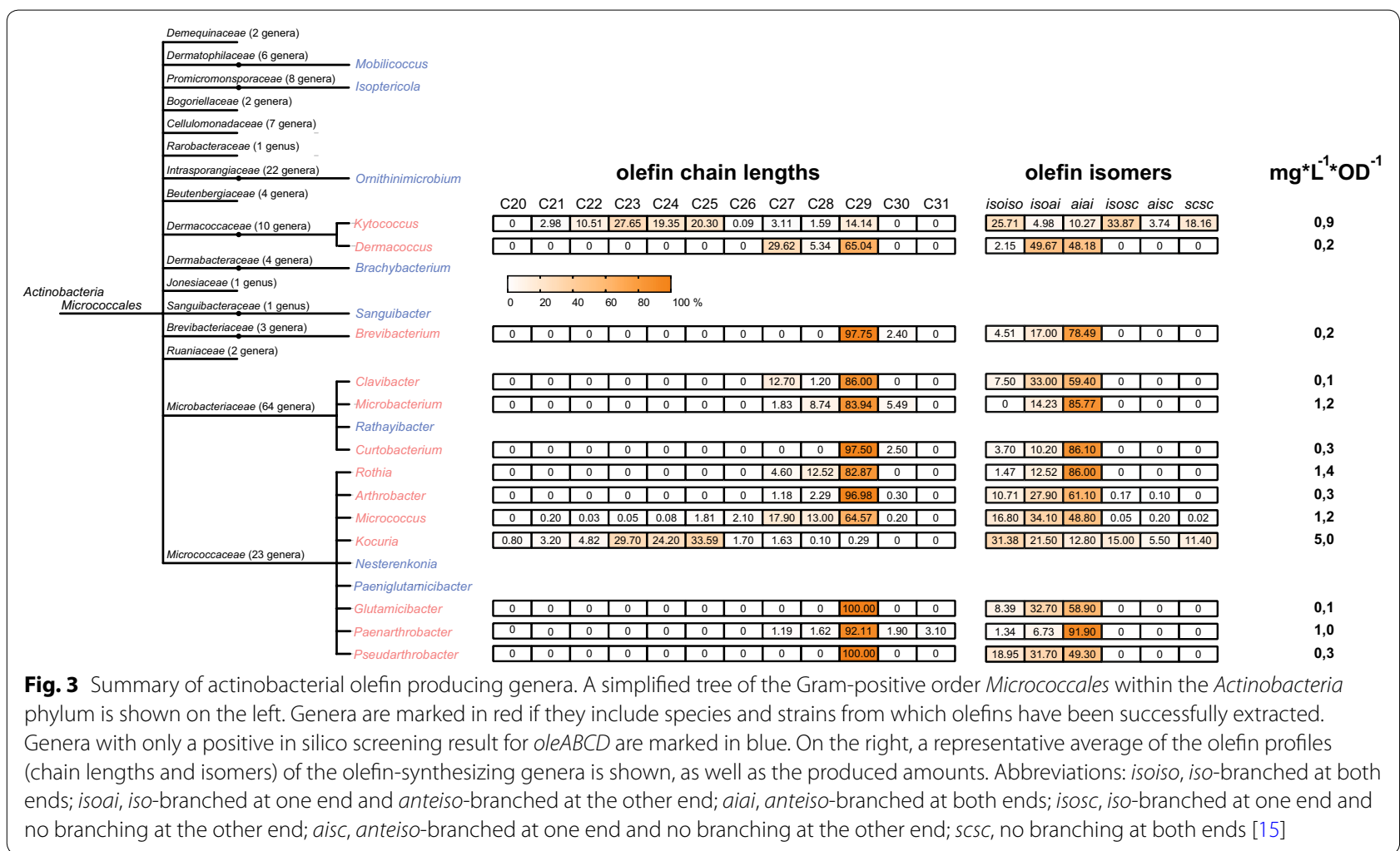

spectrum of the strain Dermacoccus sp. blue KL114 was an exception, with a shifted chain length ranging from 15 to 18 carbon atoms, especially iso-branched fatty acids and greater shares of unsaturated fatty acids. The spectrum of Microbacterium imperiale was special because of the greater shares of cyclic fatty acids (Additional file 5: Figure S5).

\section{Substrate specificity of OleA determines olefin profiles}

Despite sharing similar fatty acid spectra, there were obvious differences in the olefin profiles among the Kocuria, Kytococcus, and the rest of the Micrococcales strains. In order to study the underlying reasons for these differences, we generated recombinant strains in which the native ole genes or ole gene clusters of the $M$. luteus trpE16 strain were replaced by foreign gene or gene cluster homologs. In those strains, the native $M$. luteus ole $A B C D$ or oleA genes were replaced with the corresponding genes from Kocuria, Kytococcus, or other Micrococcus strains. In olefin synthesis, the initial condensation reaction between two fatty acid substrates is catalyzed by the condensing thiolase OleA. Thus, it can be expected that the substrate specificity of olefin synthesis is mainly determined by the affinity of OleA for specific substrates. To account for contributions by the other genes of the ole cluster, the effect of the exchange of the entire ole $A B C D$ cluster was compared to the exchange of ole $A$ alone. In order to study the effect of transferring ole genes from Kocuria sp. MAW846 (donor) to $M$. luteus (acceptor), four strains were generated and grown in complex medium to stationary phase, before analysis of their olefin profiles (Fig. 4). The Kocuria donor strain produced iso-branched as well as straight-chain olefin isomers with chain lengths of 23 to 25 carbon atoms while the $M$. luteus parental strain naturally formed the general Micrococcales ai-branched isomer-dominated profile of mainly olefins with chains 29 carbon atoms long. The transfer of the Kocuria ole $A B C D$ cluster into Micrococcus, as well as oleA alone, led to the same strong shift from ai-branched to iso-branched olefin isomers; $M$. luteus still did not produce straight-chain olefins. In addition, the transfers led to a shift in olefin chain length from 29 to 25 carbons atoms in both cases and to the same extent.

We investigated additional $M$. luteus oleA exchange mutants, using oleA genes from the strains Ko. palustris DSM 20319, Kocuria sp. 3352, Ky. sedentarius TW93, and Micrococcus sp. 2148 (series of oleAex strains, see Table 1). After growth in complex medium to stationary phase, the olefin profiles of these oleA exchange strains were again compared to the profiles of the respective donor and acceptor strains (Fig. 5). Olefin production in strain Micrococcus sp. 2148 was not as strictly dominated by olefins that were $a i$-branched and 29 carbon 
a

\begin{tabular}{|c|c|c|c|c|c|c|c|}
\hline 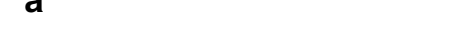 & \multicolumn{6}{|c|}{ olefin isomers } & \multirow{2}{*}{$\begin{array}{l}100 \% \\
80\end{array}$} \\
\hline $\operatorname{trpE} 16$ & 2.0 & 15.8 & 82.2 & 0 & 0 & 0 & \\
\hline trpE16 oleABCDex-MAW846M:kan & 48.0 & 39.7 & 12.3 & 0 & 0 & 0 & 60 \\
\hline trpE16 oleAex-MAW846M:kan & 50.4 & 39.8 & 9.8 & 0 & 0 & 0 & 40 \\
\hline Kocuria sp. MAW846M & 53.9 & 13.9 & 1.9 & 10.6 & 3.3 & 14.3 & 0 \\
\hline
\end{tabular}

b

olefin chain lengths

\begin{tabular}{|c|c|c|c|c|c|c|c|c|c|c|}
\hline & \multicolumn{9}{|c|}{ 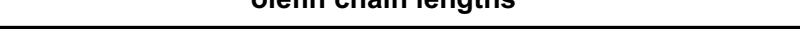 } & \multirow{2}{*}{$\begin{array}{l}100 \% \\
80\end{array}$} \\
\hline $\operatorname{trpE} 16$ & 0 & 0 & 0 & 0 & 2.3 & 1.6 & 15.7 & 7.2 & 73.2 & \\
\hline trpE16 oleABCDex-MAW846M:kan & 0 & 0 & 5.6 & 14.5 & 79.8 & 0 & 0 & 0 & 0 & 60 \\
\hline trpE16 oleAex-MAW846M:kan & 0 & 0 & 0 & 12.5 & 87.5 & 0 & 0 & 0 & 0 & 40 \\
\hline Kocuria sp.MAW846M & 1.8 & 4.1 & 26.9 & 30.5 & 32.9 & 1.8 & 0.9 & 0.1 & 0.6 & 0 \\
\hline & C21 & $\mathrm{C} 22$ & $\mathrm{C} 23$ & C24 & C25 & C26 & C27 & C28 & $\mathrm{C} 29$ & \\
\hline
\end{tabular}

Fig. 4 Olefin chain lengths and isomer distribution (in \%) of oleA and oleABCD cluster exchange mutants of Micrococcus /uteus trpE16 in complex medium compared to that from the parental strain and the Kocuria sp. MAW846M donor strain. The values are the mean of at least two biological replicates. The standard deviations of heat map values did not exceed 12\%. Abbreviations: see Fig. 3

Table 1 Micrococcus luteus trpE16 strains used in this study

\begin{tabular}{|c|c|c|}
\hline Strain & Genotype and relevant phenotype & Source \\
\hline $\operatorname{trpE} 16$ & trpE16, Trp ${ }^{-}$mutant of ATCC 27141 & Kloos and Rose [10] \\
\hline trpE16 oleAex-MAW846M:kan & $\begin{array}{l}\text { trpE16 with exchange of native oleA gene (Mlut_13230) against heterologous oleA gene from } \\
\text { Kocuria sp. MAW846M; Kan'r }\end{array}$ & This study \\
\hline trpE16 oleABCDex-MAW846M:kan & $\begin{array}{l}\text { trpE16 with exchange of native oleABCD gene cluster (Mlut_13230) against heterologous } \\
\text { oleABCD gene cluster from Kocuria sp. MAW846M; Kan }{ }^{r}\end{array}$ & This study \\
\hline ope & $\begin{array}{l}\text { trpE16 } P_{\text {up }} 13230 \text { (replacement of native oleABCD gene cluster promoter by strong succinate } \\
\text { dehydrogenase promoter) }\end{array}$ & Surger et al. [16] \\
\hline ope oleAex-2148:kan & $\begin{array}{l}\text { ope with exchange of native oleA gene (Mlut_13230) against heterologous oleA gene from } \\
\text { Micrococcus luteus 2148; } \text { Kan' }^{r}\end{array}$ & This study \\
\hline ope oleAex-20319:kan & $\begin{array}{l}\text { ope with exchange of native oleA gene (Mlut_13230) against heterologous oleA gene from Ko. } \\
\text { palustris DSM 20319; Kan' }\end{array}$ & This study \\
\hline ope oleAex-3352:kan & $\begin{array}{l}\text { ope with exchange of native oleA gene (Mlut_13230) against heterologous oleA gene from } \\
\text { Kocuria sp. 3352; Kan' }\end{array}$ & This study \\
\hline ope oleAex-TW93:kan & $\begin{array}{l}\text { ope with exchange of native oleA gene (Mlut_13230) against heterologous oleA gene from Ky. } \\
\text { sedentarius TW93; Kan' }\end{array}$ & This study \\
\hline
\end{tabular}

ope ole promoter exchange, $\mathrm{Kan}^{r}$ kanamycin resistant

atoms long as is the case in M. luteus ope (ole promoter exchange strain in which the native ole promoter was replaced by the strong succinate dehydrogenase promoter). Nevertheless, if the native oleA in $M$. luteus ope was replaced by the gene from Micrococcus sp. 2148, the produced olefin profile was not changed. The resulting recombinant $M$. luteus exchange strain produced smaller amounts than the M. luteus parental strain; however, the new OleA enzyme produced more products than in its original metabolic background in Micrococcus sp. 2148. The olefin profile of Kocuria sp. 3352 was dominated by $a i$-branched olefins, but not to the same extent as found in the M. luteus ope strain. The chain lengths of the olefins in Kocuria sp. 3352 ranged from 23 to 27 carbon atoms with an excess of 25 carbon atoms, which is four carbon atoms shorter than the dominant chain length in M. luteus (C29, 29 carbon atoms). Replacement of the native oleA in M. luteus ope by the corresponding gene from Kocuria sp. 3352 allowed M. luteus to produce straight-chain olefins in complex medium and reduced the dominance of $a i$-branched isomers for the benefit of iso-branched isomers in M. luteus. In addition, the olefin chain length was shifted from mainly 29 carbon atoms to 25 carbon atoms. The switch in oleA was accompanied by a strong loss in the productivity of olefin synthesis compared to the parental strain. Ko. palustris DSM 20319 


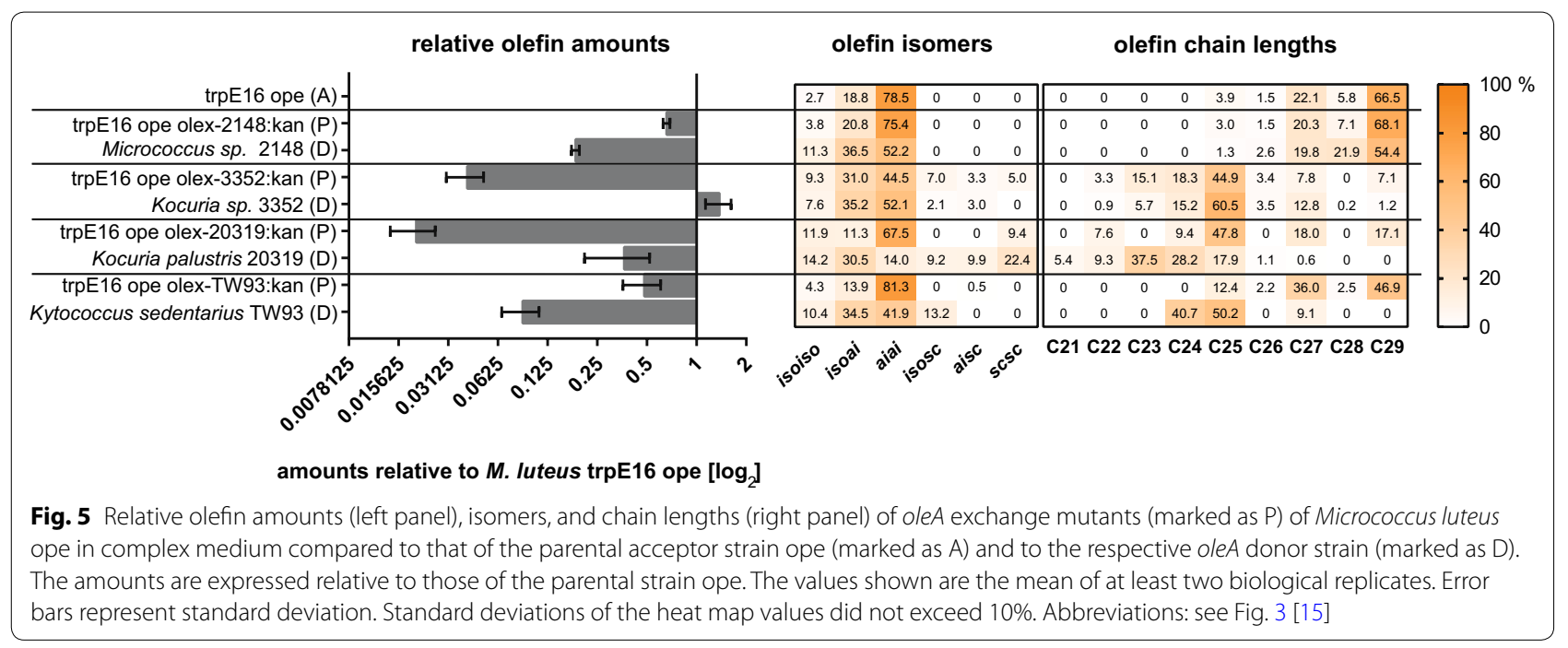

produced straight-chain, $i$ so- and $a i$-branched olefin isomers. The length of the produced chains ranged from 21 to 25 carbon atoms with most olefins being 23 carbon atoms long. The transfer of the Ko. palustris DSM 20319 oleA gene to $M$. luteus ope allowed $M$. luteus to produce straight-chain olefins in complex medium, but the dominance of $a i$-branched olefin isomers remained. The range of chain lengths in $M$. luteus ope expressing the Ko. palustris oleA gene was expanded down to 22 carbon atoms, with the majority of olefins being 25 carbon atoms long. Again, in this case the transfer of oleA was accompanied by a significant decrease in the number of olefins compared to those produced in M. luteus ope. The Kytococcus strain in complex medium produced a relatively high percentage $(>40 \%)$ of straight-chain (C24) olefins, but had an affinity for $a i$-branched chains. Predominantly chains of 24 and 25 carbon atoms length were synthesized. When oleA of $M$. luteus ope was replaced by the gene from Ky. sedentarius TW93, the olefin profile of $M$. luteus shifted slightly toward shorter chains, but was still dominated by $\mathrm{C} 29$ olefins. The spectrum of olefin isomers of this oleA exchange strain was not changed compared to that in the $M$. luteus ope parental strain. The $M$. luteus exchange strain produced less olefins than the $M$. luteus parental strain, but the new OleA enzyme was much more productive in this strain than in its original metabolic background in Ky. sedentarius TW93.

\section{Discussion}

Distribution of ole $A B C D$ genes in the bacterial domain, and diversity of olefin and fatty acid profiles in the Micrococcales order

By analysis of complete and incomplete genome sequence data, the ole $A B C D$ genes could be detected in certain lineages from five bacterial phyla, i.e., the Proteobacteria (Gamma- and Deltaproteobacteria), Planctomycetes, Verrucomicrobia, Chloroflexi and Actinobacteria, with apparently only rare occasions of lateral transfer having occurred. The order Micrococcales within the Actinobacteria phylum was the only Gram-positive order that revealed oleABCD cluster-possessing genera. Notably, we could find ole gene clusters in almost all of the species with complete genomes in the Micrococcaceae family. So far, olefin production from Gram-positive bacteria has been reported for single genera, such as Micrococcus, Kocuria, Arthrobacter, and Brevibacterium (Albro and Dittmer [1]) (Tornabene et al. [17]) (Frias et al. [8]) (Sukovich et al. [13]), but in each case only for single strains and without providing a broad picture of the distribution of olefin production. In this study, we systematically studied the olefin and fatty acids profiles from numerous strains (Additional file: 1, 2, 3, 4, 5 Figures S1-S5). We describe for the first time olefin synthesis for Pseudarthrobacter, Paenarthrobacter, Glutamicibacter, Clavibacter, Rothia, Dermacoccus, Kytococcus, Curtobacterium, and Microbacterium. The cultivation, extraction, and evaluation of in total 64 strains from 12 different genera (Curtobacterium is a homotypic synonym of Brevibacterium) of the order Micrococcales allowed both the documentation of fatty acid profiles and the identification of reference profiles for olefin production from various Gram-positive genera (Fig. 3). Most of the Gram-positive olefin producers exhibit profiles of particularly anteisobranched olefins with chain lengths from 27 to 29 carbon atoms, with the latter being the dominant length. The Kocuria and Kytococcus strains represented exceptions and exhibited the capacity to synthesize olefins that are 21 to 27 carbon atoms long, which are unbranched, 
iso-branched, and anteiso-branched in equal amounts. In those cases, there appears to be either a selection of shorter iso-branched or unbranched fatty acid substrates by the biosynthetic enzymes (see below) and/or a greater supply of such shorter substrates in the cells. Olefin production was detected in all genera with available genome sequences containing ole gene orthologs for which lipid profiles of strains were analyzed in this study. Therefore, it is likely that also the other genera with sequenced genomes containing ole genes (marked blue in Fig. 3) are capable of olefin biosynthesis and produce olefins as components of their lipids.

\section{Substrate specificity of OleA that determines the olefin profile}

The question to what extent the observed differences in the olefin profiles of Kocuria and Kytococcus strains as compared to M. luteus are determined by fatty acid metabolism and by the specificity of the OleABCD enzymes was addressed by swapping ole genes. After replacing the native ole $A B C D$ cluster as well as only the native oleA of $M$. luteus trpE16 with the corresponding genes from Kocuria strains (Figs. 3, 4), the olefin profile of the M. luteus ole exchange strains clearly mirrored the isomer and chain length distributions of the Kocuria ole gene donor strains. This indicates that the substrate specificity of OleA alone is the most important determinant of the olefin profile of the bacterial host. The supply of sufficient amounts of fatty acid substrates fitting the specificity of the strain's OleA enzyme presumably represents another determining factor because the change of the olefin profile in $M$. luteus caused by introduction of the heterologous Kocuria oleA genes was accompanied by a drop of the produced olefin amounts (Fig. 4). Apparently, the full transition to the Kocuria olefin profiles in M. luteus was, in part, restricted by the lack of iso-branched and unbranched fatty acid chains, as well as of shorter fatty acid substrates within the M. luteus metabolic background (see top rows in Fig. 4a, b). The OleA enzyme of $K$. palustris DSM 20319 apparently has a relaxed isomer specificity. Upon introduction of this OleA enzyme into M. luteus an olefin profile dominated by $a i$-branched isomers was found (Fig. 5), determined by the predominance of $a i$-branched fatty acid primers in $M$. luteus (Surger et al. [16]). As a control, the exchange of the native oleA gene of M. luteus with another Micrococcus oleA from Micrococcus sp. 2148 was also performed. Although the encoded heterologous OleA amino acid sequence differed from $M$. luteus trpE16 OleA by $22 \%$, far more than for the majority of the investigated Micrococcus strains in this study (97-99\% OleA amino acid sequence identity), it displayed the same substrate specificity and by its expression the M. luteus trpE16 olefin profile was largely retained. Thus, it can be presumed that the OleA enzymes of all of the investigated Micrococcus strains have the same substrate specificity. Compared to the natural trpE16 ope acceptor strain a drop in the olefin amounts produced was observed though, which may be caused by less effective expression or reduced activity of the heterologous OleA enzyme.

Ky. sedentarius TW93 showed an olefin profile with greater shares of iso-branched and unbranched isomers, which was dominated by 24 to 25 carbon atom chains. Nevertheless, after transferring the corresponding oleA into the $M$. luteus trpE16 ope metabolic background, the olefin isomer and chain length profiles were very similar to the parental strain $M$. luteus trpE16 ope. This was accompanied in the new metabolic background by increased olefin amounts. Presumably the Kytococcus OleA enzyme, although it shares an amino acid sequence identity of only $47 \%$ with $M$. luteus trpE16 OleA, has a similar substrate specificity as the M. luteus OleA enzyme, but this substrate preference is not supported by the provided fatty acid substrates in the donor strain background. In Ky. sedentarius TW93, the main driver for the olefin isomer and chain length profile thus appears to be the fatty acid composition available in this host and not a very specific fatty acid preference of the OleA enzyme.

\section{Conclusions}

According to the distribution of the ole $A B C D$ genes, olefin biosynthesis via the ole pathway is restricted to five bacterial phyla, and spreading of this trait by horizontal gene transfer appears to have occurred only rarely during evolution. Among the Micrococcales within the Actinobacteria phylum, the only Gram-positive order where the ole genes were found, most olefin producers exhibit profiles of particularly anteiso-branched olefins with chain lengths from 27 to 29 carbon atoms, with the exception of Kocuria and Kytococcus strains which synthesize shorter olefins of 21 to 27 carbon atoms length. Gene swapping experiments using $M$. luteus as a host organism demonstrate that the substrate specificity of OleA, besides the fatty acid composition available, is the key determinant for the olefin profile produced. These results can serve as a foundation for future research to engineer (i) the substrate specificity of this important class of enzymes and/ or (ii) the fatty acyl-CoA precursor pool in the producer cells with the aim to construct strains tailored to produce specific olefins for industrial applications.

\section{Materials and methods}

\section{Bacterial strains and growth conditions}

A tryptophan auxotroph of M. luteus (formerly, M. lysodeikticus) ISU, trpE16 (Kloos and Rose [10]) (Angelov 
et al. [2]), and its derivatives (Table 1) were grown in lysogeny broth (LB) or modified Naylor medium at $30^{\circ} \mathrm{C}$. $M$. luteus trpE16 was used as a host for DNA manipulations and as a reference strain. Naylor medium had a $\mathrm{pH}$ of 7.2 and contained per liter $10 \mathrm{~g}$ sodium glutamate $\times \mathrm{H}_{2} \mathrm{O}, 7$ g glucose, $5 \mathrm{~g} \mathrm{NH}_{4} \mathrm{Cl}, 2 \mathrm{~g} \mathrm{~K}_{2} \mathrm{HPO}_{4}, 100 \mathrm{mg}$ $\mathrm{MgSO}_{4} \times 7 \mathrm{H}_{2} \mathrm{O}, 100 \mathrm{mg}$ tryptophan, $10 \mathrm{mg}$ biotin, $4 \mathrm{mg}$ $\mathrm{FeSO}_{4} \times 7 \mathrm{H}_{2} \mathrm{O}$, and $2 \mathrm{mg} \mathrm{MnCl}_{2} \times 4 \mathrm{H}_{2} \mathrm{O}$ and was prepared using ultrapure water. Where appropriate, the growth media were supplemented with $60 \mu \mathrm{g} / \mathrm{mL}$ kanamycin. All the other Micrococcales strains (Table 2) were grown in $\mathrm{LB}$ at $30^{\circ} \mathrm{C}$ to stationary phase and used for olefin as well as total fatty acid extraction.

\section{Production of the phylogenetic tree}

The phylogenetic analysis for the presence/absence of ole gene clusters was performed using the following pipeline: putative OleA proteins were first obtained using the PROSITE search pattern EPxx[AS]x(14,18)DxxNACL against the $\mathrm{nr}$ database. Bacterial genomes with potential ole cluster were further verified by searching for ole $B C D$ gene homologs in the close vicinity of the ole $A$ gene $( \pm 5000 \mathrm{bp}$, using $M$. luteus OleBC and OleD as queries and blastp cutoff $e<=10^{-5}$ ). Incomplete bacterial genomes with no OleA hits as well as OleA hits with no support for clustering with OleBCD were discarded. The list of complete bacterial genomes was obtained from Ensembl genomes release 38 (https://ensemblgenomes. org/pub/bacteria/release-38). The data about the presence of ole gene clusters was mapped on the phylogenetic tree of Segata et al. [12] which contains 3737 genomes (data available on https://github.com/angelovangel/oleAdistribution-paper-dataset). The phylogenetic tree was generated with the ggtree package in R (Yu et al. [18]).

\section{OleA sequence similarity network (SSN)}

The similarity network analysis was performed using the EFI Enzyme Similarity server (https://efi.igb.illinois. edu/efi-est/, Gerlt et al. [9]). For this analysis, a total of 1349 putative OleA protein sequences were used, which resulted in 939 nodes in the SSN. The generated network used a similarity threshold of $\mathrm{E}<10^{-5}$, i.e., proteins with this or higher level of amino acid sequence similarity are connected with edges. The length of the edges is proportional to the similarity score. Proteins with level of amino acid sequence identity higher than $75 \%$ were represented as one node.

\section{Construction of $M$. luteus ole $A B C D$ and oleA exchange (olex) mutants}

Homologous regions of DNA sequences upstream and downstream of gene insertion sites, selection markers, and heterologous gene sequences were amplified by polymerase chain reaction (PCR) using Q5 polymerase (New England Biolabs). The Gibson assembly method (New England Biolabs) was used to assemble the PCR products with overlaps. The in vitro Gibson assembly reactions $(\sim 0.2-0.4 \mu \mathrm{g}$ DNA) were added directly to $M$. luteus cells for uptake via natural transformation and plated on LB plates supplemented with the appropriate antibiotic, as described previously (Angelov et al. [2]). The correctness of the alterations in the M. luteus genome was confirmed by PCR and the sequencing of the target genomic regions. Table 1 lists the $M$. luteus strains used in this study.

\section{Olefin extraction}

Micrococcus luteus and other Micrococcales cultures were grown at $30{ }^{\circ} \mathrm{C}$ to stationary phase and $10-\mathrm{mL}$ samples were taken. The samples were centrifuged in glass vials with polytetrafluoroethylene (PTFE) screw caps. The cell pellets were resuspended in residual supernatant and $100 \mu \mathrm{L} 100 \%$ acetic acid was added and thoroughly mixed. One milliliter of methanol and $4 \mathrm{~mL}$ hexane, amended with 10 or $50 \mu \mathrm{g} / \mathrm{mL}$ triacontane (Tokyo Chemical Industry) as an internal standard, were added. The mixture was shaken overnight at $640 \mathrm{rpm}$ in a KS 130B shaker to extract the maximum amount of olefins possible. To facilitate phase separation, the samples were centrifuged and the upper hexane phase was used for analysis.

\section{Lipid and free fatty acid extraction}

The cultures were grown to stationary phase and 2.5$\mathrm{mL}$ samples were transferred to glass vials with PTFE screw caps. The cell suspension was thoroughly mixed with $100 \mu \mathrm{L} 100 \%$ acetic acid, after which $500 \mu \mathrm{L} 100 \mu \mathrm{g} /$ $\mathrm{mL}$ eicosanoic acid (Larodan $\mathrm{AB}$ ) solution in ethanol as an internal standard and $5 \mathrm{~mL}$ methanol/chloroform (1:1) were added. The mixture was shaken overnight at $640 \mathrm{rpm}$ and after centrifugation, the lower chloroform phase was transferred to a new glass vial and completely evaporated. Lipid and free fatty acids were methylated by adding $500 \mu \mathrm{L} 1.2 \mathrm{M}$ hydrochloric acid in methanol and incubating at $50{ }^{\circ} \mathrm{C}$ overnight while shaking. The esterification reaction was quenched by adding $5 \mathrm{~mL} 100 \mathrm{mg} /$ $\mathrm{mL}$ aqueous $\mathrm{NaHCO}_{3}$. Finally, the fatty acid methyl esters (FAMEs) were extracted with $1 \mathrm{~mL}$ hexane, and the hexane phase was transferred into a GC/MS vial for analysis.

\section{Gas chromatography/mass spectrometry}

A QP2020 gas chromatograph/mass spectrometer (Shimadzu Corp.) was used to perform the GC/MS analysis. The gas chromatograph was equipped with a split or splitless injection system and a Rxi-5 ms $(30 \mathrm{~m} \times 0.25 \mathrm{~mm}$ i.d. $\times 0.25 \mu \mathrm{m})$ capillary column, and 
Table 2 Other Micrococcales strains used in this study

\begin{tabular}{|c|c|c|}
\hline Strain & Database number and synonyms & Source \\
\hline Arthrobacter agilis ${ }^{\mathrm{a}}$ & Micrococcus agilis (basonym) & $\begin{array}{l}\text { TUM Chair of Microbiology strain collection (K. H. } \\
\text { Schleifer, 614) }\end{array}$ \\
\hline Arthrobacter atrocyaneus & LMG 3814, ATCC 13752 & $\begin{array}{l}\text { TUM Chair of Microbiology strain collection (K. H. } \\
\text { Schleifer, 454) }\end{array}$ \\
\hline Arthrobacter aurescens & DSM 20116, LMG 3815 & $\begin{array}{l}\text { TUM Chair of Microbiology strain collection (K. H. } \\
\text { Schleifer, 84/487) }\end{array}$ \\
\hline Arthrobacter citreus & LMG 16338, DSM 20133 & $\begin{array}{l}\text { TUM Chair of Microbiology strain collection (K. H. } \\
\text { Schleifer, 447/256) }\end{array}$ \\
\hline Arthrobacter crystallopoietes & LMG 3819, DSM 20117 & $\begin{array}{l}\text { TUM Chair of Microbiology strain collection (K. H. } \\
\text { Schleifer, 85/440) }\end{array}$ \\
\hline Arthrobacter oxydans & LMG 3816, DSM 20119 & $\begin{array}{l}\text { TUM Chair of Microbiology strain collection (K. H. } \\
\text { Schleifer, 91/486) }\end{array}$ \\
\hline Arthrobacter polychromogenes & LMG 16679, DSM 20136 & $\begin{array}{l}\text { TUM Chair of Microbiology strain collection (K. H. } \\
\text { Schleifer, 522) }\end{array}$ \\
\hline Arthrobacter sp. ${ }^{a}$ & Filibacter limicola (designation in collection) & $\begin{array}{l}\text { TUM Chair of Microbiology strain collection (K. H. } \\
\text { Schleifer, 424) }\end{array}$ \\
\hline Arthrobacter sulfureus & LMG 16694, DSM 20167 & $\begin{array}{l}\text { TUM Chair of Microbiology strain collection (K. H. } \\
\text { Schleifer, 523) }\end{array}$ \\
\hline Arthrobacter uratoxydans & LMG 16220, ATCC 21749 & $\begin{array}{l}\text { TUM Chair of Microbiology strain collection (K. H. } \\
\text { Schleifer, 461) }\end{array}$ \\
\hline Brevibacterium casei & ATCC 35513, NCDO 2048 & $\begin{array}{l}\text { TUM Chair of Microbiology strain collection (K. H. } \\
\text { Schleifer, 491) }\end{array}$ \\
\hline Brevibacterium casei & NCDO 2050, WS 2124 & $\begin{array}{l}\text { TUM Chair of Microbiology strain collection (K. H. } \\
\text { Schleifer, 492) }\end{array}$ \\
\hline Brevibacterium sp. Ap13 & - & $\begin{array}{l}\text { Fecal sample, Laguna Aparejos, Argentina, (J. Dib, } \\
\text { PROIMI-CONICET) }\end{array}$ \\
\hline $\begin{array}{l}\text { Clavibacter michiganensis sp. } \\
\text { nebraskensis }\end{array}$ & DSM 7483 & DSMZ \\
\hline Curtobacterium albidum & $\begin{array}{l}\text { LMG 8759, Brevibacterium albidum (homotypic syno- } \\
\text { nym) }\end{array}$ & $\begin{array}{l}\text { TUM Chair of Microbiology strain collection (K. H. } \\
\text { Schleifer, 465) }\end{array}$ \\
\hline Curtobacterium citreum & LMG 8786, Brevibacterium citreum (homotypic synonym) & $\begin{array}{l}\text { TUM Chair of Microbiology strain collection (K. H. } \\
\text { Schleifer, 457) }\end{array}$ \\
\hline $\begin{array}{l}\text { Curtobacterium flaccumfaciens pv. } \\
\text { Betae }\end{array}$ & $\begin{array}{l}\text { LMG 3596, Corynebacterium flaccumfaciens pv. Betae } \\
\text { (homotypic synonym) }\end{array}$ & $\begin{array}{l}\text { TUM Chair of Microbiology strain collection (K. H. } \\
\text { Schleifer, 485) }\end{array}$ \\
\hline Curtobacterium luteum & LMG 8787, Brevibacterium luteum (homotypic synonym) & $\begin{array}{l}\text { TUM Chair of Microbiology strain collection (K. H. } \\
\text { Schleifer, 460) }\end{array}$ \\
\hline Curtobacterium pusillum & $\begin{array}{l}\text { LMG 8788, Brevibacterium pusillum (homotypic syno- } \\
\text { nym) }\end{array}$ & $\begin{array}{l}\text { TUM Chair of Microbiology strain collection (K. H. } \\
\text { Schleifer, 449) }\end{array}$ \\
\hline Dermacoccus sp. blue KL114 & M. or blue (designation in collection) & $\begin{array}{l}\text { TUM Chair of Microbiology strain collection (K. H. } \\
\text { Schleifer, 606) }\end{array}$ \\
\hline Glutamicibacter nicotinae & $\begin{array}{l}\text { DSM 20123, ATCC 15236, Arthrobacter nicotinae (baso- } \\
\text { nym) }\end{array}$ & $\begin{array}{l}\text { TUM Chair of Microbiology strain collection (K. H. } \\
\text { Schleifer, 451/86) }\end{array}$ \\
\hline Glutamicibacter protophormiae & $\begin{array}{l}\text { LMG 16324, DSM 20168, Arthrobacter protophormiae } \\
\text { (basonym) }\end{array}$ & $\begin{array}{l}\text { TUM Chair of Microbiology strain collection (K. H. } \\
\text { Schleifer, 467) }\end{array}$ \\
\hline Ko. palustris DSM 11925 & CCM 4949, NBRC 16318 & DSMZ \\
\hline Ko. palustris DSM $20319^{a}$ & DBM 385, Micrococcus varians (basonym) & DSMZ \\
\hline Ko. palustris DSM $20320^{a}$ & KH 113, Micrococcus varians (basonym) & DSMZ \\
\hline Kocuria rosea & ATCC 186, NCTC 7523, Micrococcus roseus (basonym) & TUM Chair of Microbiology strain collection (W. Liebl) \\
\hline Kocuria rosea ${ }^{a}$ & ATCC 186, NCTC 7523, Micrococcus roseus (basonym) & $\begin{array}{l}\text { TUM Chair of Microbiology strain collection (K. H. } \\
\text { Schleifer, 615) }\end{array}$ \\
\hline Kocuria sp. $3312^{\mathrm{a}}$ & - & $\begin{array}{l}\text { Skin/nail/mucosal (M. Köberle TUM Department of } \\
\text { Dermatology and Allergology) }\end{array}$ \\
\hline Kocuria sp. $3352^{\mathrm{a}}$ & - & $\begin{array}{l}\text { Skin/nail/mucosal (M. Köberle TUM Department of } \\
\text { Dermatology and Allergology) }\end{array}$ \\
\hline Kocuria sp. AT3343a & M. luteus AT3343 (designation in collection) & TUM Chair of Microbiology strain collection (W. Liebl) \\
\hline Kocuria sp. MAW846M & Micrococcus varians (designation in collection) & TUM Chair of Microbiology strain collection (W. Liebl) \\
\hline
\end{tabular}


Table 2 (continued)

\begin{tabular}{|c|c|c|}
\hline Strain & Database number and synonyms & Source \\
\hline Ky. sedentarius TW93 & $\begin{array}{l}\text { ATCC 14392, DSM 20547, Micrococcus sedentarius } \\
\text { (basonym) }\end{array}$ & TUM Chair of Microbiology strain collection (W. Liebl) \\
\hline Microbacterium imperiale & WS 1959, Brevibacterium imperiale (basonym) & $\begin{array}{l}\text { TUM Chair of Microbiology strain collection (K. H. } \\
\text { Schleifer, 489) }\end{array}$ \\
\hline M. aurantiacus & ATCC 11731 & TUM Chair of Microbiology strain collection (W. Liebl) \\
\hline M. luteus A31658 & - & TUM Chair of Microbiology strain collection (W. Liebl) \\
\hline M. luteus ATCC 15800 & ML 53-40 & TUM Chair of Microbiology strain collection (W. Liebl) \\
\hline M. luteus ATCC 27141 & JCM 3347 & TUM Chair of Microbiology strain collection (W. Liebl) \\
\hline M. luteus CCM 1339 & - & TUM Chair of Microbiology strain collection (W. Liebl) \\
\hline M. luteus DSM 20030 & ATCC 4698, CCM 169 & TUM Chair of Microbiology strain collection (W. Liebl) \\
\hline M. luteus JW6 & - & $\begin{array}{l}\text { TUM Chair of Microbiology strain collection (W. } \\
\text { Liebl/K. H. Schleifer, 600) }\end{array}$ \\
\hline M. luteus MAW843 & - & TUM Chair of Microbiology strain collection (W. Liebl) \\
\hline M. luteus MAW845M & - & TUM Chair of Microbiology strain collection (W. Liebl) \\
\hline M. luteus VM3 & - & TUM Chair of Microbiology strain collection (W. Liebl) \\
\hline M. Iylae TW226 & ATCC 27566, DSM 20315 & TUM Chair of Microbiology strain collection (W. Liebl) \\
\hline Microbacterium imperiale & WS 1959, Brevibacterium imperiale (basonym) & $\begin{array}{l}\text { Skin/nail/mucosal (M. Köberle TUM Department of } \\
\text { Dermatology and Allergology) }\end{array}$ \\
\hline Micrococcus sp. $1306^{\mathrm{a}}$ & - & $\begin{array}{l}\text { Skin/nail/mucosal (M. Köberle TUM Department of } \\
\text { Dermatology and Allergology) }\end{array}$ \\
\hline Micrococcus sp. $2105^{\mathrm{a}}$ & & $\begin{array}{l}\text { Skin/nail/mucosal (M. Köberle TUM Department of } \\
\text { Dermatology and Allergology) }\end{array}$ \\
\hline Micrococcus sp. $2148^{\mathrm{a}}$ & - & $\begin{array}{l}\text { Skin/nail/mucosal (M. Köberle TUM Department of } \\
\text { Dermatology and Allergology) }\end{array}$ \\
\hline Micrococcus sp. $2181^{a}$ & - & $\begin{array}{l}\text { Skin/nail/mucosal (M. Köberle TUM Department of } \\
\text { Dermatology and Allergology) }\end{array}$ \\
\hline Micrococcus sp. $2228^{\mathrm{a}}$ & - & $\begin{array}{l}\text { Skin/nail/mucosal (M. Köberle TUM Department of } \\
\text { Dermatology and Allergology) }\end{array}$ \\
\hline Micrococcus sp. $2525^{\mathrm{a}}$ & - & $\begin{array}{l}\text { Skin/nail/mucosal (M. Köberle TUM Department of } \\
\text { Dermatology and Allergology) }\end{array}$ \\
\hline Micrococcus sp. $2559^{a}$ & - & $\begin{array}{l}\text { Skin/nail/mucosal (M. Köberle TUM Department of } \\
\text { Dermatology and Allergology) }\end{array}$ \\
\hline Micrococcus sp. $3185^{\mathrm{a}}$ & - & Laguna Diamante, Argentina (J. Dib, PROIMI-CONICET) \\
\hline Micrococcus sp. 69 & - & Laguna Diamante, Argentina (J. Dib, PROIMI-CONICET) \\
\hline Micrococcus sp. 70 & - & $\begin{array}{l}\text { Water sample, Laguna Azul, Argentina (J. Dib, PROIMI- } \\
\text { CONICET) }\end{array}$ \\
\hline Micrococcus sp. A1 & - & $\begin{array}{l}\text { Water sample, Laguna Azul, Argentina (J. Dib, PROIMI- } \\
\text { CONICET) }\end{array}$ \\
\hline Micrococcus sp. A7 & - & TUM Chair of Microbiology strain collection (W. Liebl) \\
\hline Micrococcus sp. D12 & - & $\begin{array}{l}\text { Sediment sample, Laguna Diamante, Argentina (J. Dib, } \\
\text { PROIMI-CONICET) }\end{array}$ \\
\hline Micrococcus sp. H5 & - & $\begin{array}{l}\text { Water sample, Laguna Huaca Huasi, Argentina (J. Dib, } \\
\text { PROIMI-CONICET) }\end{array}$ \\
\hline Micrococcus sp. V7 & - & $\begin{array}{l}\text { Water sample, Laguna Vilama, Argentina (J. Dib, } \\
\text { PROIMI-CONICET) }\end{array}$ \\
\hline Paenarthrobacter ilicis & $\begin{array}{l}\text { DSM 20138, LMG 3659, Arthrobacter illicis, Corynebacte- } \\
\text { rium ilicis (basonym) }\end{array}$ & $\begin{array}{l}\text { TUM Chair of Microbiology strain collection (K. H. } \\
\text { Schleifer (469/90) }\end{array}$ \\
\hline Pseudarthrobacter chlorophenolicus & DSM 12829 & DSMZ \\
\hline Rothia sp. ${ }^{\text {a }}$ & $\begin{array}{l}\text { DSM 20321, ATCC } 27572, \text { Micrococcus kristinae (designa- } \\
\text { tion in collection) }\end{array}$ & TUM Chair of Microbiology strain collection (W. Liebl) \\
\hline
\end{tabular}

ATCC American Type Culture Collection, CCM Czech Collection of Microorganisms, DBM Collection of Yeasts and Industrial Microorganisms, DSMZ German Collection of Microorganisms and Cell Cultures, JCM Japan Collection of Microorganisms, LMG Laboratorium voor Microbiologie en Microbiele Genetica, NBRC Biological Resource Center, National Institute of Technology and Evaluation (NITE), NCDO National Collection of Dairy Organisms (today incorporated into NCIMB National Collection of Industrial, Food and Marine Bacteria), WS Microorganism Collection Weihenstephan

a For some strains, the strain designation was confirmed by $16 \mathrm{~S}$ rDNA sequencing 
MS was operated under ionization by electron impact at $70 \mathrm{eV}$ and $200{ }^{\circ} \mathrm{C}$. The $1-\mu \mathrm{L}$ samples were injected in the split or splitless mode. Helium flow was maintained at $1 \mathrm{~mL} / \mathrm{min}$. The temperature of the column and duration was $40{ }^{\circ} \mathrm{C}$ for $3 \mathrm{~min}$, then increased to $280{ }^{\circ} \mathrm{C}$ at $20{ }^{\circ} \mathrm{C} /$ $\mathrm{min}$, and finally held for $5 \mathrm{~min}$ for FAMEs or $8 \mathrm{~min}$ for olefins. Mass spectra were recorded at $\mathrm{m} / \mathrm{z}$ (mass/charge) $45-500$ at a rate of $0.2 / \mathrm{s}$.

The extractable olefins were quantified by directly comparing their peak areas with that of triacontane (C30 alkane, 30 carbon atoms) of known concentration, which had been added to the hexane used to extract the olefins. FAMEs were quantified by directly comparing their peak areas with that of eicosanoic acid (C20:0) of known concentration, which had been added to the sample at the beginning of the extraction procedure. For comparison of the olefin amounts produced by different Micrococcales strains, the quantitative data were normalized to a culture density of $\mathrm{OD}_{600}=1$.

\section{Supplementary information}

Supplementary information accompanies this paper at https://doi. org/10.1186/s13068-020-01706-y.

Additional file 1: Figure S1. Arthrobacter strains. The total fatty acid and olefin chain lengths and isomer distribution, as well as absolute cellular amounts in complex medium. Values are the mean of at least two biological replicates. The error bars represent standard deviation. Except for Arthrobacter oxydans, which was $<15 \%$, the standard deviations of the heat map values did not exceed $2 \%$. Abbreviations: isoiso, iso-branched at both ends; isoai, iso-branched at one end and anteiso-branched at the other end; aiai, anteiso-branched at both ends; isosc, iso-branched at one end and no branching at the other end; aisc, anteiso-branched at one end and no branching at the other end; SCSC, no branching at both ends; even iso, iso-branched even-numbered; odd iso, iso-branched odd-numbered; ai, anteiso-branched; sc, straight chain; br, branched; br-un, branched and unsaturated; sc-un, straight chain and unsaturated; OD, optical density [15].

Additional file 2: Figure S2. Brevibacterium/Curtobacterium strains. The total fatty acid and olefin chain lengths and isomer distributions, as well as absolute cellular amounts in complex medium. The values are the mean of at least two biological replicates. The error bars represent standard deviation. Except for Brevibacterium casei (Schleifer, 492), which was <6\%, standard deviations of the heat map values did not exceed 3\%. Notes: *homotypic synonyms of Brevibacterium. Abbreviations: cyclo, cyclic fatty acids; for other abbreviations see Additional file: 1 Figure S1 [15].

Additional file 3: Figure S3. Kocuria strains. The total fatty acid and olefin chain lengths and isomer distributions, as well as absolute cellular amounts in complex medium. The values are the mean of at least two biological replicates. The error bars represent standard deviation. Except for Kocuria sp. MAW846M, which was $<6 \%$, the standard deviations of the heat map values did not exceed 3\%. Abbreviations: see Additional file: 1 Figure S1 [15].

Additional file 4: Figure S4. Micrococcus strains. The total fatty acid and olefin chain lengths and isomer distributions, as well as absolute cellular amounts in complex medium. The values are the mean of at least two biological replicates. The error bars represent standard deviation. Except for Micrococcus luteus A31655 and M. aurantiacus, which were $<12 \%$, the standard deviations of the heat map values did not exceed 5\%. Abbreviations: see Additional file: 1 Figure S1 [15].
Additional file 5: Figure S5. Diverse Micrococcales strains. The total fatty acid and olefin chain lengths and isomer distributions, as well as absolute cellular amounts in complex medium. The values are the mean of at least two biological replicates. The error bars represent standard deviation. The standard deviations of the heat map values did not exceed $7 \%$. Abbreviations: cyclo, cyclic fatty acids; for other abbreviations see Additional file: 1 Figure S1 [15].

\section{Abbreviations}

ai-branched: Anteiso-branched; aiai-branched: Anteiso-branched at both ends; cis-configured: The main substituents of the double bond are orientated to the same side of the molecule; C20:0: 20 carbon atoms and no double bond; C24: 24 carbon atoms; C29: 29 carbon atoms; C30: 30 carbon atoms; FAME: Fatty acid methyl ester; GC/MS: Gas chromatography/mass spectrometry; high-GC: High guanine plus cytosine content of the genome; isoiso-branched: Iso-branched at both ends; LB: Lysogeny broth; m/z: Mass/charge; ole: Olefin biosynthesis pathway; olex: OleA or oleABCD exchange mutants; PCR: Polymerase chain reaction; SSN: Sequence similarity network.

\section{Acknowledgements}

The authors are grateful to J. Dib (PROIMI-CONICET, Tucuman, Argentina) and M. Köberle (TUM Department of Dermatology and Allergology, Munich, Germany) for supplying some actinobacterial strains investigated in this study.

\section{Authors' contributions}

MS, AA and WL contributed to the design of the experiments and interpretation of the data. MS and AA carried out the experimental work for data acquisition and analysis. MS, AA and WL wrote the manuscript. AA and WL revised the text critically. All authors read and approved the final manuscript.

\section{Funding}

Financial support from the German Federal Ministry of Food and Agriculture (BMEL, Grant Number FKZ 22007913) is gratefully acknowledged.

\section{Availability of data and materials}

The datasets analyzed for generation of the phylogenetic tree during the current study are available on Github, [https://github.com/angelovangel/ oleA-distribution-paper-dataset]. The residual data generated or analyzed during this study are included in this published article [and its supplementary information files].

\section{Ethics approval and consent to participate}

Not applicable.

\section{Consent for publication}

All authors read and approved the final manuscript.

\section{Competing interests}

The authors declare that they have no competing interests.

Received: 27 January 2020 Accepted: 2 April 2020

Published online: 15 April 2020

\section{References}

1. Albro PW, Dittmer JC. The biochemistry of long-chain, nonisoprenoid hydrocarbons. I. Characterization of the hydrocarbons of Sarcina lutea and the isolation of possible intermediates of biosynthesis. Biochemistry. 1969;8:394-405.

2. Angelov A, Bergen P, Nadler F, Hornburg P, Lichev A, Übelacker M, et al. Novel Flp pilus biogenesis-dependent natural transformation. Front Microbiol. 2015:6:1-11.

3. Beller HR, Goh EB, Keasling JD. Genes involved in long-chain alkene biosynthesis in Micrococcus luteus. Appl Environ Microbiol. 2010;76:1212-23.

4. Christenson JK, Richman JE, Jensen MR, Neufeld JY, Wilmot CM, Wackett LP. $\beta$-Lactone synthetase found in olefin biosynthesis pathway. Biochemistry. 2016;56:348-51. 
5. Christenson JK, Jensen MR, Goblirsch BR, Mohamed F, Zhang W, Wilmot CM, et al. Active multi-enzyme assemblies for long-chain olefinic hydrocarbon biosynthesis. J Bacteriol. 2017;199:1-11.

6. Christenson JK, Robinson SL, Engel A, Richman JE, Kim AN, Wackett LP. OleB from bacterial hydrocarbon biosynthesis is a $\beta$-lactone decarboxylase that shares key features with haloalkane dehalogenases. Biochemistry. 2017;56:5278-87.

7. Frias JA, Richman JE, Erickson JS, Wackett LP. Purification and characterization of OleA from Xanthomonas campestris and demonstration of a non-decarboxylative claisen condensation reaction. J Biol Chem. 2011;286:10930-8.

8. Frias JA, Richman JE, Wackett LP. C29 olefinic hydrocarbons biosynthesized by Arthrobacter species. Appl Environ Microbiol. 2009;75:1774-7.

9. Gerlt JA, Bouvier JT, Davidson DB, Imker HJ, Sadkhin B, Slater DR, Whalen KL. Enzyme Function Initiative-Enzyme Similarity Tool (EFI-EST): a web tool for generating protein sequence similarity networks. Biochim Biophys Acta. 2015;1854:1019-37.

10. Kloos WE, Rose NE. Transformation mapping of tryptophan loci in Micrococcus luteus. Genetics. 1970;66:595-605.

11. Pfleger B, Gossing M, Nielsen J. Metabolic engineering strategies for microbial synthesis of oleochemicals. Metab Eng. 2015;29:1-11.

12. Segata N, Börnigen D, Morgan XC, Huttenhower C. PhyloPhIAn is a new method for improved phylogenetic and taxonomic placement of microbes. Nat Commun. 2013;4:1-23.

13. Sukovich DJ, Seffernick JL, Richman JE, Gralnick JA, Wackett LP. Widespread head-to-head hydrocarbon biosynthesis in bacteria and role of OleA. Appl Environ Microbiol. 2010;76:3850-62.
14. Sukovich DJ, Seffernick J Richman JE, Hunt KA Gralnick JA Wackett LP. Structure, function, and insights into the biosynthesis of a head-to-head hydrocarbon in Shewanella oneidensis strain MR-1. Appl Environ Microbiol. 2010;76:3842-9.

15. Surger M. Charakterisierung und Modifizierung der Kohlenwasserstoffproduktion in Mikrokokken [dissertation]. Munich, Germany: Technical University of Munich; 2018. http://nbn-resolving.de/urn/resolver. pl?urn:nbn:de:bvb:91-diss-20180807-1442044-1-3. Accessed 30 Nov 2019.

16. Surger $M$, Angelov $A$, Stier $P$, Übelacker $M$, Liebl W. Impact of branched chain amino acid catabolism on fatty acid and alkene biosynthesis in Micrococcus luteus. Front. Microbiol. 2018;8:1-14.

17. Tornabene TG, Gelpi E, Oro J. Identification of fatty acids and aliphatic hydrocarbons in Sarcina lutea by gas chromatography and combined gas chromatography-mass spectrometry. J Bacteriol. 1967;94:333-43.

18. Yu G, Smith DK, Zhu H, Guan Y, Lam TTY. GGTREE: an R package for visualization and annotation of phylogenetic trees with their covariates and other associated data. Methods Ecol Evol. 2017;8:28-36.

\section{Publisher's Note}

Springer Nature remains neutral with regard to jurisdictional claims in published maps and institutional affiliations.
Ready to submit your research? Choose BMC and benefit from:

- fast, convenient online submission

- thorough peer review by experienced researchers in your field

- rapid publication on acceptance

- support for research data, including large and complex data types

- gold Open Access which fosters wider collaboration and increased citations

- maximum visibility for your research: over 100M website views per year

At BMC, research is always in progress.

Learn more biomedcentral.com/submissions 